\title{
TOURIST BEHAVIOUR AND TICK-BORNE DISEASE RISK
}

\author{
ALYSSA SOUCY \& SANDRA DE URIOSTE-STONE \\ School of Forest Resources, University of Maine, USA
}

\begin{abstract}
Lyme disease is the leading tick-borne disease in the USA, with incidences increasing over the past few decades due in part to climate change. Visitors to natural areas involved in nature-based activities are at a heightened risk of Lyme disease exposure. We surveyed 430 visitors in Acadia National Park to understand the personal protective behaviours and associated barriers to adoption, perceived tick-borne disease risk, and travel behaviour. A two-step cluster analysis revealed two visitor segments: adventurists and sightseers. Adventurists were less likely to perform protective behaviours against tick-borne disease, but performing a tick check was the most commonly reported preventative behaviour for both groups $(62 \%)$. The most commonly cited barriers to performing a tick check were lower perceived risk of tick bites and Lyme disease for both groups. Both groups also reported that the number one barrier to wearing protective clothing was the hot summer weather. This research has implications for tourism managers to design effective communication materials to reduce the risk of tick-borne disease for different visitor segments.
\end{abstract}

Keywords: nature-based tourism, cluster analysis, Lyme disease, Acadia National Park, ticks, health risk, survey research, Maine.

\section{INTRODUCTION}

Lyme disease (LD), transmitted through the bite of an infected blacklegged tick, is the most commonly diagnosed tick-borne disease (TBD) in the United States, with over 42,000 reported cases in 2017 [1]. Lyme disease poses a significant threat to those travelling to rural areas partaking in outdoor activities [2]. Risks may be heightened for tourists unaware of LD who lack the necessary knowledge and resources to properly protect themselves [3]. On the other hand, impacts from localized climate change, such as increases in LD risk, can impact the quality of the visitor experience [4] and their decisions regarding future travel plans [5]. For that reason, exposure to LD has major implications for both visitors and tourism managers. The purpose of this study is to analyse the role of activity type and associated factors that may influence personal protective behaviours against TBD in Acadia National Park, Maine, United States of America.

Tick-borne disease risk management primarily focuses on protective measures to reduce TBD risk. Personal protective measures include using insect repellents containing DEET, avoiding contact with ticks, performing tick checks after recreating outdoors, and showering within 2 hours of coming indoors [6]. Despite the wide range of protective measures against TBD and high knowledge of LD symptoms, uptake has been poor [7], [8]. Large differences exist in the type of protective measure used among the public, with performing a tick check as the most commonly reported behaviour [9], [10] and using insect repellent as the least commonly reported [11]. Similarly, there have been disparities in the effectiveness of education to increase protective behaviours [3], [12]. Hence, understanding the determinants of protective measure adoption is important to addressing this health risk.

Potential factors that may influence the uptake of protective behaviours against TBD have been extensively studied. Perceived efficacy of a given protective measure has been shown to be strongly associated with performing that measure [10]. Knowledge and concern are also significant predictors of protective behaviour [13], [14]. There do, however, exist differences in the potential drivers for the use of different protective measures. Knowledge about LD 
[15] and exposure to ticks [16] have been significantly associated with tick checks but not with other measures such as tick repellent [15].

In tourism studies the use of segmentation analysis can help compare groups of visitors with different characteristics to identify variations that exist between these groups [17] in terms of travel or health behaviours. Acadia National Park brings visitors from all over the globe who engage in a variety of recreational activities; therefore, determining if differences exist in how diverse visitor groups perceive and respond to the risk of TBD can help guide risk communication strategies that seek to increase adoption of personal protective behaviours. The goal of this study is to (a) investigate the differences in socio-demographics, perceived risk, and personal protective behaviours by visitor group; and (b) identify barriers to adopting protective behaviours by visitor group.

\section{METHODS}

\subsection{Study area}

Acadia National Park (ANP) is located in Maine, which is in the north-eastern part of the United States. Over the past several decades there have been increases in incidences of LD due in part to climate change [18]. In 2017, Maine had 1,852 Lyme diagnoses, making it the state with the highest amount of confirmed Lyme cases per 100,000 residents [19]. Tourism is one of the largest industries in the state of Maine. In particular, ANP offers a diverse range of recreation activities that attract over 3 million visitors every year, including a scenic road that loops through the entire park, guided programs and museums, more than 150 miles of trails for all skill-levels, campgrounds, and opportunities for rock climbing, kayaking, bird watching [20]. ANP was selected as our study site for the following reasons: (1) the park is the $8^{\text {th }}$ most visited National Park in the United States, with outdoor recreation as primary attraction, hence putting millions of tourists per year at risk of exposure TBD; (2) TBD is expected to increase as a result of climate change and increases visitation in the study area; (3) visitation coincides with peak periods of black-legged tick activity; and (4) a 2016 study found that ANP visitors identified heightened risk of exposure to vector-borne disease as an important concern regarding future visitation [5] that may have economic implications for nearby gateway communities.

\subsection{Survey design and sampling procedure}

The study used a mixed-mode survey, with an on-site 5-minute intercept component followed by a longer online self-administered survey. The intercept survey included sociodemographic and travel behaviour questions as well as questions regarding perceived TBD risk, and was aimed at increasing the likelihood that visitors would complete the longer selfadministered survey. The self-administered instrument consisted of questions on travel behaviour, and protective behaviours to reduce TBD risk. Data were collected between MayOctober 2018 in ANP.

Participants were selected using a two-stage cluster probability sample [21]. The sampling dates were first randomly selected and the visitor groups were then selected on-site using a systematic probability sampling technique [22]. Survey administrators approached random walking groups by using a pre-selected interval (i.e. every $3^{\text {rd }}$ group), and interviewed the person with the most recent birthday, if willing. Following the short on-site survey, participants were handed a postcard with a link to a self-administered online survey to complete once they returned home. Dillman's Tailored Design Method was used to maximize 
response rate by asking visitors for an email or mailing address in order to send up to two reminders regarding the online survey [23]. Of the 1,252 on-site surveys collected, 430 respondents completed the self-administered survey ( $34 \%$ response rate).

\subsection{Measures}

\subsubsection{Activities}

Respondents were asked to select which activities they participated in during their visit to ANP out of a list of 33 options. Respondents were then asked to select their primary activity from that same list of options. Participants were also asked if they would make changes in their future travel plans based on TBD concerns (change destination, engage in different recreational activities, change the timing of their travel).

\subsubsection{Perceived risk}

Respondents were asked to rate their responses to the question of whether or not the risks that ticks pose to humans are (1) avoidable and (2) controllable using 7-point Likert scale where $1=$ strongly agree and $7=$ strongly disagree. The two questions were combined using a mean score, where answers to both questions were required, so that higher scores indicate higher perceived risk. These two questions were highly correlated with a Pearson's correlation of 0.60 .

\subsubsection{Protective behaviour}

Participants were asked to select whether or not they engaged in 8 personal protective behaviours never, sometimes, or always. Protective behaviours included staying on trails, performing tick checks, tucking pants into socks, avoiding activities that expose one to ticks, avoiding recreating outdoors, using insect repellent, wearing light-coloured clothing, and wearing protective clothing. Responses were coded so that $0=$ never, $1=$ sometimes, and $2=$ always. A sum score was calculated so that higher scores reflect higher overall protective behaviour $(\alpha=0.76)$. Scores are out of 16 .

\subsubsection{Barriers to protective behaviours}

If a participant did not select always for the following protective behaviours: performing tick checks or wearing protective clothing, they were asked to select their top three barriers to that behaviour out of a list of 5 options. Both behaviours listed: there is a low chance of getting Lyme disease, there is a low chance of getting bit by a tick, and that behaviour is overdone as potential barriers. Other barriers for performing tick checks included not knowing how to remove a tick and not knowing how to recognize a tick. Responses were coded so that 1 indicates a top barrier and 0 indicates that that is not a top barrier.

\subsubsection{Socio-demographics}

Lastly, a range of socio-demographics was collected including age, gender $(0=$ female; $1=$ male), education collapsed into two categories where $0=$ higher education (college degree); 1 = lower education (no college degree), their home state/country $(1=$ states with $\mathrm{LD} ; 2=$ all other $)$, and whether or not they are a $1^{\text {st }}$ time visitor to ANP $\left(0=1^{\text {st }}\right.$ time visitor; $1=$ repeat visitor).

\subsection{Data analysis}

There were a total of 430 responses to the self-administered survey. Non-response bias was measured using Pearson's chi-square test of independence $\left(\chi^{2}\right)$ to compare those who 
responded to the on-site survey $(n=1252)$ with those who completed the self-administered survey $(n=429)$. There was no statistical differences in first time visitation $\left(\chi^{2}=1.45,1 \mathrm{df}\right.$, $p=0.23)$, knowledge of what a tick is $\left(\chi^{2}=2.85,1 \mathrm{df}, p=0.09\right)$, and gender $\left(\chi^{2}=2.44,1 \mathrm{df}\right.$, $p=0.12)$; however, there was a statistical difference in experience with TBD $\left(\chi^{2}=5.31,1\right.$ df, $p=0.02$ ) with those taking the on-site survey having relatively fewer experience with TBD compared to those taking the self-administered survey. It is possible that those who have personally experienced TBD were more interested in the study and therefore were more inclined to take the self-administered survey, which would account for this difference.

A multivariate two-step cluster analysis was run to segment ANP visitors. Cluster analysis can be useful in the context of tourism and parks management as means to understand visitor group needs [24]. Clustering was based off of the number of nature-based activities (either somewhat nature-based or nature-based) and whether the primary activity was nature based (Table 1) as modified by the procedure used in Wilkins et al. [25].

Independent samples t-tests were used to test for differences for the continuous variables of perceived risk, and protective behaviour. Levene's statistic was used to test the assumption of equal variances of groups. If homogeneity of variance was violated an adjustment was made using the Welch-Satterthwaite method [26]. Cohen's d was used to assess effect size for independent samples and Welch's t-test results. Chi-square tests were run to examine the differences in activity groups for each protective behaviour. Cramer's V was used for effect size and adjusted standardized residuals (ASR) were used as a post-hoc test, with those two standard deviations or more away from the expected mean reported. Barriers to protective behaviours against TBD were investigated using descriptive statistics. The proportion of respondents who selected each barrier was calculated for each group using the number of respondents who did not always perform that protective behaviour. All data analyses were done in SPSS 25.0.

Table 1: Categorization of types of activities listed used for two-step cluster analysis.

\begin{tabular}{|l|l|}
\hline Categories & Activities \\
\hline $\begin{array}{l}\text { Not nature-based } \\
(0)\end{array}$ & $\begin{array}{l}\text { Arts or cultural activity, Concert or festival, Dining at Jordan Pond } \\
\text { House }\end{array}$ \\
\hline Sightseers (1) & Sightseeing or driving for pleasure \\
\hline $\begin{array}{l}\text { Somewhat } \\
\text { nature-based (2) }\end{array}$ & $\begin{array}{l}\text { Bird Watching, Going to the beach, Picking berries, Picnicking, } \\
\text { Taking horse or carriage ride, Trail running, Walking my dog, } \\
\text { Wildlife viewing }\end{array}$ \\
\hline Nature-based (3) & $\begin{array}{l}\text { Backpacking, Biking, Camping, Hiking, Kayaking, Non-technical } \\
\text { mountain climbing, Walking on carriage roads, Swimming }\end{array}$ \\
\hline
\end{tabular}

\section{RESULTS}

\subsection{Demographic profile, trip characteristics, and potential travel behaviour change}

As shown in Table 2, the majority of respondents were non-residents of Maine (93\%) with $54 \%$ from areas with LD and 39\% from areas without LD. Most respondents (61\%) were first time visitors, travelling with family (78\%). The 60-69 year age group had the most respondents $(28 \%)$ followed by the 50-59 age group (22\%) and then the $40-49$ age group $(20 \%)$. Finally, there was a majority female sample $(60 \%)$. In addition, almost half of the respondents selected hiking on trails $(49 \%)$ as their primary activity with sightseeing as the 
second most selected response (27\%), and biking as the third $(7 \%)$. Over a quarter of respondents participated in the following activities at ANP: hiking on trails $(76 \%)$, sightseeing/driving for pleasure (75\%), going to the beach (40\%), viewing wildlife $(39 \%)$, shopping in the park (36\%), and dining at Jordan Pond House (28\%). Further, when asked about changes in travel behaviour resulting from concerns with TBD, 35\% of participants expressed that they would change their travel destination, 26\% would change their outdoor recreation activities, while $17 \%$ would consider traveling during another time of year.

Table 2: Socio-demographics, trip characteristics and potential travel behaviour change.

\begin{tabular}{|l|l|c|c|}
\hline Variable & Subcategory & $\begin{array}{c}\text { No. of } \\
\text { responses }\end{array}$ & Percent \\
\hline \multirow{3}{*}{ Residency } & Maine & 25 & $7 \%$ \\
& Areas with Lyme Disease & 187 & $54 \%$ \\
& All other areas & 137 & $39 \%$ \\
\hline \multirow{2}{*}{ First time visitation to ANP } & First time visitors & 253 & $61 \%$ \\
& Repeat visitors & 164 & $39 \%$ \\
\hline \multirow{5}{*}{ Type of personal group } & Alone & 15 & $4 \%$ \\
& Family & 296 & $78 \%$ \\
& Friends & 44 & $12 \%$ \\
& Family and Friends & 25 & $7 \%$ \\
\hline \multirow{5}{*}{ Age (years) } & $<30$ & 27 & $7 \%$ \\
& $30-39$ & 55 & $15 \%$ \\
& $40-49$ & 72 & $20 \%$ \\
& $50-59$ & 80 & $22 \%$ \\
\multirow{2}{*}{ Gender } & $60-69$ & 101 & $28 \%$ \\
& $>69$ & 154 & $8 \%$ \\
\hline \multirow{2}{*}{ Travel behaviour change } & Male & 229 & $60 \%$ \\
\hline from TBD concern & Female & 135 & $35 \%$ \\
& Change destination & 98 & $26 \%$ \\
& Change in outdoor activities & 66 & $17 \%$ \\
\hline
\end{tabular}

\subsection{Recreation activity groups and their differences}

The clustering analysis resulted in two visitor segments: adventurists and sightseers (Table $3)$. Adventurists were those who participated in more nature-based activities $(M=4.5)$ and whose primary activity was nature-based, measured on a scale from $0-3(M=3.0)$. Sightseers were those who participated in fewer nature-based activities $(M=2.5)$ and whose primary activity was less-nature based $(M=1.2)$. Table 4 shows there is no significant difference in gender $\left(\chi^{2}(1, N=374)=1.21, p=0.27\right)$ or first time visitation $\left(\chi^{2}(1, N=303)=2.52\right.$, $p=0.11)$. Education and region were significantly different between activity groups, with adventurists tending to be more highly educated $\left(\chi^{2}(1, N=374)=1.21, p=0.27\right)$ and from areas with the presence of $\operatorname{LD}\left(\chi^{2}(1, N=350)=8.58, p=0.00\right)$.

As shown in Table 5, t-tests elicited no significant differences between activity groups in perceived risk $(t(1)=0.15, p=0.88)$. Overall, sightseers $(M=7.97)$ reported performing protective behaviours against TBD more often than adventurists $(M=7.27)$ on a scale from 0 to $16(t(1)=-2.02, p=0.03)$; the overall protective behaviour comprises 8 measures. 
Table 3: Descriptions and characteristics of the two activity visitor groups (clusters).

\begin{tabular}{|l|l|l|}
\hline Visitor group & Adventurists & Sightseers \\
\hline Description & $\begin{array}{l}\text { Tourists who tended to } \\
\text { participate in more nature-based } \\
\text { activities and whose primary } \\
\text { activity was nature-based, like } \\
\text { hiking, camping, etc. }\end{array}$ & $\begin{array}{l}\text { Tourists who tended to participate } \\
\text { in fewer nature-based activities and } \\
\text { whose primary activity was less } \\
\text { nature-based, such as sightseeing }\end{array}$ \\
\hline Size & $260(65 \%)$ & $143(35 \%)$ \\
\hline Inputs & $\begin{array}{l}\text { Mean number of nature-based } \\
\text { activities: } 4.49 \\
\text { Primary activity nature-based: } \\
3.0\end{array}$ & $\begin{array}{l}\text { Mean number of nature-based } \\
\text { activities: } 2.53 \\
\text { Primary activity nature-based: } 1.15\end{array}$ \\
\hline
\end{tabular}

Table 4: Comparisons of socio-demographics and trip characteristics broken down by activity group (reported as percentages).

\begin{tabular}{|c|c|c|c|c|}
\hline Variable & $\begin{array}{c}\text { Adventurists } \\
(\%)\end{array}$ & $\begin{array}{c}\text { Sightseers } \\
(\%)\end{array}$ & $\begin{array}{c}\text { Chi-square } \\
\text { (sig) }\end{array}$ & $\begin{array}{c}\text { Cramer's V } \\
\left(\Phi_{C}\right)\end{array}$ \\
\hline $\begin{array}{l}\text { Gender } \\
\text { Male } \\
\text { Female }\end{array}$ & $\begin{array}{c}N=236 \\
38 \\
62\end{array}$ & $\begin{array}{c}N=138 \\
43 \\
57\end{array}$ & $1.21(0.27)$ & 0.06 \\
\hline $\begin{array}{c}\text { Home state/country } \\
\text { Areas with LD } \\
\text { All other areas }\end{array}$ & $\begin{array}{c}N=219 \\
66 \\
44\end{array}$ & $\begin{array}{c}N=131 \\
50 \\
50\end{array}$ & $8.58(0.00)$ & 0.16 \\
\hline $\begin{array}{l}\text { Education } \\
\text { Lower education } \\
\text { Higher education }\end{array}$ & $\begin{array}{c}N=238 \\
8 \\
92\end{array}$ & $\begin{array}{c}N=138 \\
20 \\
80\end{array}$ & $10.91(0.00)$ & 0.17 \\
\hline $\begin{array}{l}\text { Visitation } \\
\text { First time visitor } \\
\text { Repeat visitor } \\
\end{array}$ & $\begin{array}{c}N=260 \\
57 \\
43\end{array}$ & $\begin{array}{c}N=143 \\
65 \\
35\end{array}$ & $2.52(0.11)$ & 0.08 \\
\hline
\end{tabular}

Table 5: Comparisons of perceived risk and protective behaviour broken down by activity group (reported as mean values).

\begin{tabular}{|l|c|c|c|c|c|}
\hline Variable & $\begin{array}{c}\text { Adventurists } \\
(\mathbf{N})\end{array}$ & $\begin{array}{c}\text { Sightseers } \\
(\mathbf{N})\end{array}$ & $\begin{array}{c}\text { Levene } \\
\text { Stat (sig) }\end{array}$ & t-test (sig) & $\begin{array}{c}\text { Cohen's } \\
\text { D }\end{array}$ \\
\hline Perceived risk & $2.65(241)$ & $2.63(138)$ & $1.58(0.21)$ & $0.15(0.88)$ & 0.01 \\
\hline $\begin{array}{l}\text { Protective } \\
\text { behaviour }\end{array}$ & $7.27(244)$ & $7.97(137)$ & $7.79(0.01)$ & $\begin{array}{c}-2.02 \\
(0.03)\end{array}$ & 0.24 \\
\hline
\end{tabular}

When examining individual protective behaviours, there is no significant difference in performing a tick check $\left(\chi^{2}(2, N=379)=5.36, p=0.07\right)$ or using insect repellent $\left(\chi^{2}(2, N=370)=1.38, p=0.50\right)$ between adventurists and sightseers as shown in Table 6 . There are, however, a relatively larger percentage of sightseers $(8 \%)$ who never perform a tick check compared to adventurists (3\%). Despite this, performing a tick check is the most commonly performed protective behaviour for both groups $(62 \%$ always perform a tick check). The significant difference in overall protective behaviour can be attributed to 
Table 6: Comparisons of types of protective behaviours against TBD broken down by activity group (reported as percentages).

\begin{tabular}{|c|c|c|c|c|c|}
\hline Variable & $\begin{array}{c}\text { Overall } \\
(\%)\end{array}$ & $\begin{array}{c}\text { Adventurists } \\
(\%)\end{array}$ & $\begin{array}{l}\text { Sightseers } \\
(\%)\end{array}$ & $\begin{array}{l}\text { Chi- } \\
\text { square } \\
\text { (sig) }\end{array}$ & $\begin{array}{c}\text { Cramer's } \\
\text { V }\left(\Phi_{C}\right)\end{array}$ \\
\hline $\begin{array}{l}\text { Performing a tick } \\
\text { check } \\
\text { Never } \\
\text { Sometimes } \\
\text { Always }\end{array}$ & $\begin{array}{c}N=387 \\
5 \\
33 \\
62\end{array}$ & $\begin{array}{c}N=244 \\
\\
\quad 3 * \\
34 \\
63\end{array}$ & $\begin{array}{c}N=135 \\
\\
8^{*} \\
32 \\
60\end{array}$ & $\begin{array}{c}5.36 \\
(0.07)\end{array}$ & 0.20 \\
\hline $\begin{array}{l}\text { Wearing protective } \\
\text { clothing } \\
\text { Never } \\
\text { Sometimes } \\
\text { Always } \\
\end{array}$ & $\begin{array}{c}N=384 \\
9 \\
66 \\
25\end{array}$ & $\begin{array}{c}\mathrm{N}=242 \\
10 \\
72^{*} \\
18^{*}\end{array}$ & $\begin{array}{c}N=134 \\
8 \\
56^{*} \\
36^{*}\end{array}$ & $\begin{array}{l}14.59 \\
(0.00)\end{array}$ & 0.20 \\
\hline $\begin{array}{l}\text { Using insect repellent } \\
\text { Never } \\
\text { Sometimes } \\
\text { Always } \\
\end{array}$ & $\begin{array}{c}N=388 \\
9 \\
54 \\
37 \\
\end{array}$ & $\begin{array}{c}N=244 \\
9 \\
56 \\
35 \\
\end{array}$ & $\begin{array}{c}N=136 \\
7 \\
52 \\
40 \\
\end{array}$ & $\begin{array}{l}1.38 \\
(0.50)\end{array}$ & 0.06 \\
\hline $\begin{array}{l}\text { Avoiding activities } \\
\text { that will expose to } \\
\text { ticks } \\
\text { Never } \\
\text { Sometimes } \\
\text { Always } \\
\end{array}$ & $\begin{array}{c}N=388 \\
41 \\
54 \\
5\end{array}$ & $\begin{array}{c}N=244 \\
\\
41 \\
57 \\
2 *\end{array}$ & $\begin{array}{l}N=135 \\
\\
42 \\
50 \\
8^{*}\end{array}$ & $\begin{array}{c}9.84 \\
(0.01)\end{array}$ & 0.16 \\
\hline $\begin{array}{l}\text { Avoiding recreating } \\
\text { outdoors } \\
\text { Never } \\
\text { Sometimes } \\
\text { Always } \\
\end{array}$ & $\begin{array}{c}N=385 \\
\\
41 \\
54 \\
5\end{array}$ & $\begin{array}{c}N=243 \\
83 * \\
16 \\
1\end{array}$ & $\begin{array}{c}N=133 \\
74 * \\
23 \\
3\end{array}$ & $\begin{array}{c}6.37 \\
(0.04)\end{array}$ & 0.13 \\
\hline $\begin{array}{l}\text { Staying on paved } \\
\text { trails/gravel } \\
\text { Never } \\
\text { Sometimes } \\
\text { Always }\end{array}$ & $\begin{array}{c}N=386 \\
14 \\
67 \\
19\end{array}$ & $\begin{array}{c}N=244 \\
15 \\
70 \\
15^{*}\end{array}$ & $\begin{array}{c}N=134 \\
12 \\
63 \\
25^{*}\end{array}$ & $\begin{array}{c}6.07 \\
(0.05)\end{array}$ & 0.13 \\
\hline $\begin{array}{l}\text { Tucking pants into } \\
\text { socks } \\
\text { Never } \\
\text { Sometimes } \\
\text { Always } \\
\end{array}$ & $\begin{array}{c}N=386 \\
41 \\
44 \\
15 \\
\end{array}$ & $\begin{array}{c}N=244 \\
46^{*} \\
44 \\
10^{*} \\
\end{array}$ & $\begin{array}{c}N=15 \\
\\
35^{*} \\
43 \\
22^{*} \\
\end{array}$ & $\begin{array}{l}11.15 \\
(0.01)\end{array}$ & 0.17 \\
\hline $\begin{array}{l}\text { Wearing light } \\
\text { coloured clothing } \\
\text { Never } \\
\text { Sometimes } \\
\text { Always }\end{array}$ & $\begin{array}{c}N=385 \\
19 \\
66 \\
15\end{array}$ & $\begin{array}{c}N=242 \\
19 \\
70^{*} \\
11^{*}\end{array}$ & $\begin{array}{c}N=135 \\
20 \\
60 * \\
20 *\end{array}$ & $\begin{array}{c}6.19 \\
(0.05)\end{array}$ & 0.13 \\
\hline
\end{tabular}

Note. Degrees of freedom $=2$ for all chi-square tests.

*Indicates adjusted standardized residual $(\mathrm{ASR})>1.96$. 
sightseers more commonly performing other protective behaviours, such as wearing protective clothing $\left(\chi^{2}(2, N=376)=14.59, p=0.00\right)$.

3.3 How do the barriers to protective behaviours differ between activity groups?

Compared with only $64 \%$ of sightseers, $82 \%$ of adventurists do not always wear protective clothing. The top overwhelming barrier for both activity groups is that it is too warm in the summer, with $93 \%$ of all respondents selecting it as one of their top 3 barriers (Fig. 1). Both adventurists and sightseers prioritized similarly other barriers to using protective clothing as a protective measure.

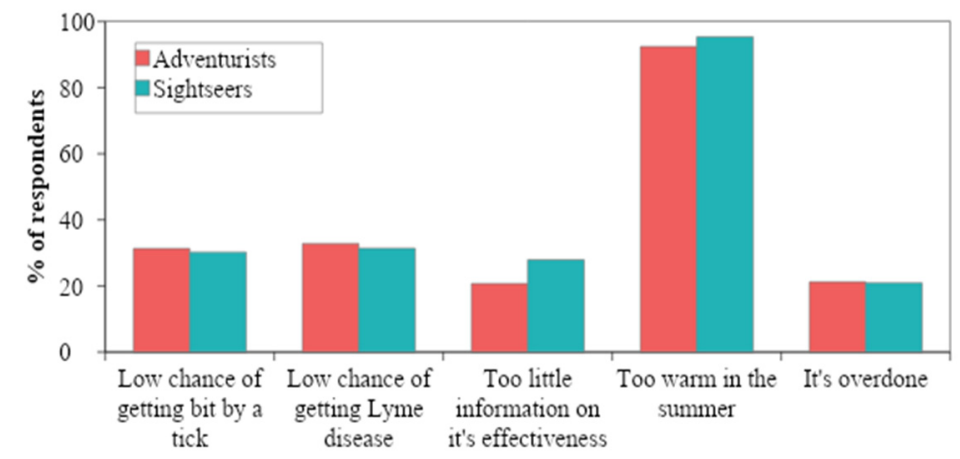

Figure 1: Bar chart of proportion of respondents who selected each barrier to wearing protective clothing for adventurists (pink) and sightseers (blue).

Approximately $40 \%$ of both activity groups do not always perform tick checks (Fig. 2). Adventurists selected there's a low chance of getting Lyme as their number one barrier to performing tick checks and there's a low chance of getting bit by a tick as their second barrier with $42 \%$ and $41 \%$ respectively. Sightseers were similar in that they selected both as their top barriers; however, $48 \%$ selected there's a low chance of getting bit by a tick and only $32 \%$ selected there's a low chance of getting Lyme as their top barriers to performing tick checks. It's overdone was the next highest barrier for adventurists with $19 \%$ of respondents

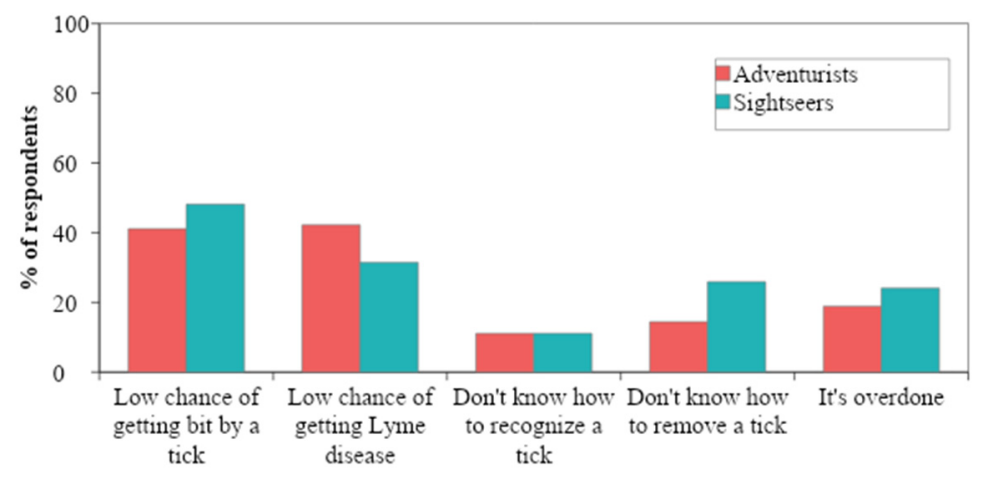

Figure 2: Bar chart of proportion of respondents who selected each barrier to performing a tick check for adventurists (pink) and sightseers (blue). 
selecting it, while I don't know how to remove a tick was the next highest barrier for sightseers with $26 \%$ choosing it as a top 3 barrier. I don't know how to recognize a tick came in last at $11 \%$ for all respondents.

\section{DISCUSSION AND CONCLUSION}

Two-step cluster analysis was an effective way to group visitors to ANP based on activity type, with those engaging in more nature-based activities such as hiking and camping (adventurists) falling into one group, while those that primarily sightsee and drive the Park Loop Road (sightseers) fall into another group. Adventurists were more likely to be highly educated and from areas with LD, while sightseers were slightly less educated and from more areas without LD. Despite the differences in socio-demographics, there were no significant differences in perceived risk of ticks between activity groups. Overall, ANP visitors surveyed tend to have low perceptions of risk, with close to $10 \%$ of respondents perceiving that risks that ticks pose are avoidable and controllable; findings are in contrast to results from a prior study in Sweden [11] that found that $43 \%$ of respondents perceive tick bites as a serious health risk.

Further, differences were found in terms of preventive behaviours, with adventurists having lower overall protective behaviour than sightseers. This is due in part to the types of behaviours measured to reduce TBD risk, such as avoiding recreating outdoors and staying on gravel/trails. It is no surprise that those that engage in more nature-based activities while visiting ANP tend to do some of those behaviours less than those who sightsee regardless of whether or not the behaviour is truly done to avoid ticks. This may also be due in part to a psychological drive to take risks to experience a rush or thrill [27], or their belief that specific TBD protective behaviours might hinder their enjoyment of their preferred recreational activities [28]. Those that engage in nature-based activities at ANP may be less-inclined to wear protective clothing or stay on trails because that would be in opposition to their desire to freely explore the natural setting. It is, however, important to note that both adventurists and sightseers are regularly performing tick checks (62\%), which is consistent with previous studies [8], [13]. Further, adventurists are wearing protective clothing less and more often not staying on trails - two protective measures specifically aimed at reducing TBD risk. From a management perspective, this is an important finding given that adventurists are inherently at higher risk of TBD due to the nature of their activities.

The top barrier to wearing protective clothing for both activity groups was that it is too warm in the summer; this finding is similar to those from previous studies [13], [29]. Other top barriers for wearing protective clothing and performing a tick check were a perceived low risk of getting bit by a tick and contracting Lyme disease; these compares findings from previous studies [13]. While it may be difficult to target warm weather as a barrier, increasing visitor's perceptions about the true risks of getting bit by a tick and contracting LD may increase preventative behaviours. More sightseers expressed their inability to remove a tick as a barrier to performing a tick check. While adventurists were relatively more knowledgeable about this, understanding the proper way to remove a tick may be an important way to increase tick checks in sightseers.

Although knowledge can inform risk perceptions and behaviours, research is needed to better understand the factors that determine perceptions of risk, and the drivers and barriers to visitor adoption of TBD protective behaviours while visiting natural settings, like national parks. Factors such as self-efficacy [8], [10], [30]; disgust about ticks [30]; perceived likelihood of being bitten by a tick [14], [30]; likelihood and severity of contracting a TBD [8], [13]; and barriers to adoption [13], may be important in predicting protective behaviours. 
The results of this study demonstrate the existence of two main visitor groups to ANP: adventurists and sightseers. Sightseers perform more protective behaviours compared to adventurists. The differences in overall protective behaviour may be due to a variety of factors including the behaviours measured in the survey instrument or adventurists inherent inclination to take more risks; however, performing a tick check is relatively high for both groups. Targeting other protective behaviours such as using insect repellent or wearing protective clothing may require communication strategies that include information about how to properly remove ticks (aimed at sightseers) to increase self-efficacy [30], and the actual risk of contracting a TBD (aimed at adventurists). Risk communication strategies targeted to specific group characteristics will be important to increase risk perception and adoption of protective behaviours [31]. Further research can examine the drivers of protective behaviours in both groups and explore the role of barriers and self-efficacy in preventing certain types of protective behaviours.

\section{ACKNOWLEDGEMENTS}

This research was supported by the University of Maine Senator George J. Mitchell Center, National Oceanic and Atmospheric Administration under grant NA17OAR4310249, and National Science Foundation under grant 1828466. The authors thank study participants; staff from the National Park Service and Acadia National Park for their support; and UMaine undergraduate students - Asha DiMatteo-LePape, Nathaniel Burke, Hope Kohtala - and Lydia Horne for their dedication to data collection.

\section{REFERENCES}

[1] Centers for Disease Control and Prevention, Tickborne disease surveillance data summary. www.cdc.gov/ticks/data-summary/index.html. Accessed on: 14 May 2020.

[2] Donohoe, H., Pennington-Gray, L. \& Omodior, O., Lyme disease: Current issues, implications, and recommendations for tourism management. Tourism Management, 46, pp. 408-418, 2015.

[3] Daltroy, L.H., Phillips, C., Lew, R., Wright, E., Shadick, N.A. \& Liang, M.H., A controlled trial of a novel primary prevention program for Lyme disease and other tickborne illnesses. Health Education and Behavior, 34, pp. 531-542, 2007.

[4] Brownlee, M.T.J., Hallo, J.C. \& Krohn, B.D., Botanical garden visitors' perceptions of local climate impacts: Awareness, concern, and behavioral responses. Managing Leisure, 18(2), pp. 97-117, 2013.

[5] De Urioste-Stone, S.M., Le, L., Scaccia, M.D. \& Wilkins, E., Nature-based tourism and climate change risk: Visitors' perceptions in Mount Desert Island, Maine. Journal of Outdoor Recreation and Tourism, 13, pp. 57-65, 2016.

[6] Centers for Disease Control and Prevention, Preventing ticks bites. www.cdc.gov/ ticks/avoid/on_people.html. Accessed on: 15 May 2020.

[7] Valente, S.L., Wemple, D., Ramos, S., Cashman, S.B. \& Savageau, J.A., Preventive behaviors and knowledge of tick-borne illnesses: Results of a survey from an endemic area. Journal of Public Health Management and Practice, 21(3), 2015.

[8] Shadick, N.A., Daltroy, L.H., Phillips, C.B., Liang, U.S. \& Liang, M.H., Determinants of tick-avoidance behaviors in an endemic area for Lyme disease. American Journal of Preventive Medicine, 13(4), pp. 265-270, 1997.

[9] Butler, A.D., Sedghi, T., Petrini, J.R. \& Ahmadi, R., Tick-borne disease preventive practices and perceptions in an endemic area. Ticks and Tick-Borne Diseases, 7(2), 331-337, 2016. https://doi.org/10.1016/j.ttbdis.2015.12.003. 
[10] Aenishaenslin, C. et al., Factors associated with preventive behaviors regarding Lyme disease in Canada and Switzerland: A comparative study. BMC Public Health, 15(285), pp. 1-10, 2015.

[11] Slunge, D. \& Boman, A., Learning to live with ticks? The role of exposure and risk perceptions in protective behaviour against tick-borne diseases. PloS One, 13(6), 2018.

[12] Hayes, E.A. \& Piesman, J., How can we prevent Lyme disease? New England Journal of Medicine, 348, pp. 2424-2430, 2003.

[13] Beaujean, D., Bults, M., Steenbergen, J. \& Voeten, H., Study on public perceptions and protective behaviors regarding Lyme disease among the general public in the Netherlands: Implications for prevention programs. BMC Public Health, 13(1), pp. 225-225, 2013.

[14] Herrington, J.E., Risk perceptions regarding ticks and Lyme disease. American Journal of Preventive Medicine, 26(2), pp. 135-140, 2004.

[15] Butler, A.D., Sedghi, T., Petrini, J.R. \& Ahmadi, R., Tick-borne disease preventive practices and perceptions in an endemic area. Ticks and Tick-borne Diseases, 7(2), pp. 331-337, 2016.

[16] Slunge, D., The willingness to pay for vaccination against tick-borne encephalitis and implications for public health policy: Evidence from Sweden. PloS One, 10(12), 2015.

[17] Benson, C., Watson, P., Taylor, G., Cook, P. \& Hollenhorst, S., Who visits a national park and what do they get out of it?: A joint visitor cluster analysis and travel cost model for Yellowstone National Park. Environmental Management, 52, pp. 917-928, 2013.

[18] Süss, J., Klaus, C., Gerstengarbe, F.W. \& Werner, P.C., What makes ticks tick? Climate change, ticks, and tick-borne diseases. Journal of Travel Medicine, 15(1), pp. 39-45, 2008.

[19] Centers for Disease Control and Prevention, Reported cases of Lyme disease by state or locality, 2009-2018. www.cdc.gov/lyme/stats/tables.html. Accessed on: 14 May 2020.

[20] Acadia, National Park Service. www.nps.gov/acad/index.htm. Accessed on: 14 May 2020.

[21] Scheaffer, R.L., Mendenhall, W., Ott, R.L. \& Gerow, K.G., Elementary Survey Sampling, 7th ed., Cengage Learning: Boston, 2012.

[22] Wilkins, E. \& De Urioste-Stone, S.M., Place attachment, recreational activities, and intended future visitation under climate change conditions. Journal of Sustainable Tourism, 26(5), pp. 798-811, 2018.

[23] Dillman, D.A., Smyth, J.D. \& Christian, L.M., Internet, Phone, Mail, and Mixed-Mode Surveys: The Tailored Design Method, 4th ed., Wiley: Hoboken, 2014.

[24] Zanon, D., Hall, J., Lockstone-Binney, L. \& Weber, D., Development of a whole agency approach to market segmentation in parks. Journal of Leisure Research, 46(5), pp. 563-592, 2014.

[25] Wilkins, E., De Urioste-Stone, S.M., Weiskittel, A. \& Gabe, T., Weather sensitivity and climate change perceptions of tourists: A segmentation analysis. Tourism Geographies, 20(2), pp. 273-289, 2018.

[26] Delacre, M., Lakens, D. \& Leys, C., Why psychologists should by default use Welch's t-test instead of Student's t-test. International Review of Social Psychology, 30(1), p. 92, 2017.

[27] Gstaettner, A.M., Lee, D. \& Rodger, K., The concept of risk in nature-based tourism and recreation: A systematic literature review. Current Issues in Tourism, 21(15), pp. 1784-1809, 2018. 
[28] Omodior, O., Pennington-Gray, L. \& Donohoe, H., Efficacy of the theory of planned behavior in predicting the intention to engage in tick-borne disease personal protective behavior amongst visitors to an outdoor recreation center. Journal of Park and Recreation Administration, 33(2), pp. 37-53, 2015.

[29] Jones, E.H., Chanlongbutra, A., Wong, D., Cunningham, F. \& Feldman, K.A., Knowledge, attitudes, and practices regarding Lyme disease prevention among employees, day visitors, and campers at Greenbelt Park. Park Science, 32(2), pp. 4653, 2015-2016.

[30] Mowbray, F., Amlot, R. \& Rubin, G.J., Predictors of protective behaviour against ticks in the UK: A mixed methods study. Ticks and Tick Borne Diseases, 5(4), pp. 392-400, 2014.

[31] Aenishaenslin, C., Bouchard, C., Koffi, J.K., Pelcat, Y. \& Ogden, N.H., Evidence of rapid changes in Lyme disease awareness in Canada. Ticks and Tick-borne Diseases, 7(6), pp. 1067-1074, 2016. 